\section{U.S.S.R. to Host 1st International Workshop on High Gravity Materials Processing}

The First International Workshop on Materials Processing at High Gravity will be held May 20-24, 1991 in Dubna, near Moscow. The Workshop is being sponsored by the U.S.S.R. Academy of Sciences, the European Materials Research Society, the Council of Europe, and others.

Experiments in directional solidification, performed in large centrifuges in the U.S.S.R., Czechoslovakia, and France, have shown that, under some conditions, crystals are produced with a higher perfection and compositional homogeneity than those produced at $1 \mathrm{~g}$ or in space. This meeting will examine the results of recent high gravity experiments, offer explanations, and develop plans for future experimental, theoretical, and modeling research.

Members of the organizing committee include chair L. Regel, Space Research Institute, Moscow; and co-chairs M. Rodot, CNRS, France, and W.R. Wilcox, Clarkson University, U.S.A. Members of the International Scientific Committee include $A$. Chevy, France; G. Labrosse, France; S. Motakef, U.S.A.; G. Müller, Germany; T. Nishinaga, Japan; R. Parfenyev, U.S.S.R.; R. Schmidt, U.S.A.; R. Smith, Canada; A. Triska, Czechoslovakia; and $\mathrm{H}$. Wiedemeyer, U.S.A.

Papers are being solicited for workshop sessions on results of experiments, theoretical modeling, centrifuge design and op- eration, and the basic science of transport phenomena and materials processing at high gravity, especially in centrifuges. Vapor crystal growth, melt growth, solution growth and glass formation will be included. The processing of semiconductors, metals, and inorganic compounds will also be discussed.

Titles and brief abstracts of proposed presentations are due to the organizers by January 20, 1991. Please list your address, telephone and fax numbers on the abstract. Transmission by fax is preferred. To submit an abstract or obtain more information, contact: L. Regel, Space Research Institute, Moscow, U.S.S.R., fax 7-095-3107023; W.R. Wilcox, Clarkson University, Potsdam, NY, 13699, U.S.A., fax 1-315-2686438; or M. Rodot, CNRS, Meudon, France, fax 33-1-4534-4696.

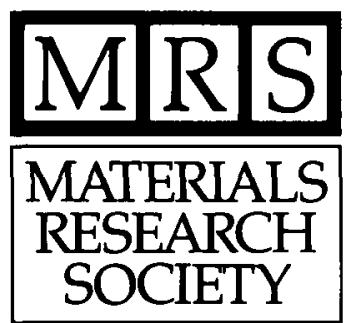

\title{
Graduate Student Award Applications Being Accepted for 1991 MRS Spring Meeting
}

The MRS Awards Committee is accepting applications for Graduate Student Awards to be presented at the 1991 MRS Spring Meeting in Anaheim, California. "The MRS Graduate Student Awards are designed to recognize outstanding research, and they have become extremely competitive," said Kathy Taylor, chair of the MRS graduate awards subcommittee. "Many outstanding graduate students participate in the MRS meetings and are candidates for these awards."

A group of finalists will be identified based on the award application. All the finalists, who will receive a waiver of the 1991 Spring Meeting registration fee, will be notified on March 15, 1991. All finalists will be required to give a 10-minute talk (based on their symposium paper) at a special student presentation session on Tuesday noon, April 30, at the 1991 Spring Meeting. Award winners, who will also receive a $\$ 250$ cash prize and a plaque, will be announced at the Plenary Session on Wednesday evening, May 1, 1991.

Applicants must be registered graduate students whose thesis research is closely related to a symposium topic addressed at the 1991 Spring Meeting. Applicants must be the author or co-author of a paper but need not actually present it. MRS membership is not required, but a student must attend the Spring Meeting to receive an award.

For information and application forms, contact the Materials Research Society, 9800 McKnight Road, Pittsburgh, PA 15237; telephone (412) 367-3003; fax (412) 3674373.

Applications Due February 1, 1991

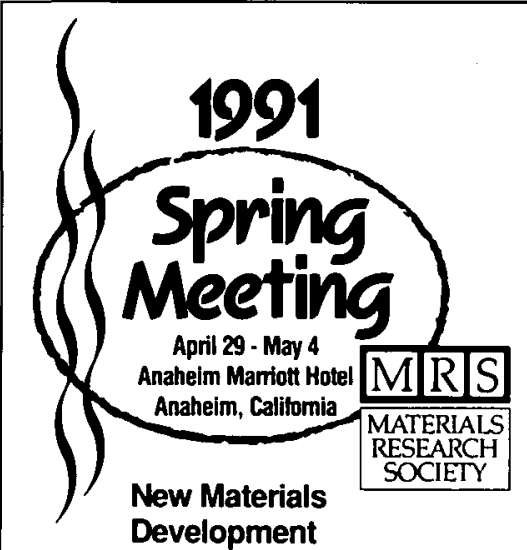

New Characterization Methods

New Process

Technology

\section{Technical Program}

A: Amorphous Silicon Technology - 1991

B: Silicon Molecular Beam Epitaxy

C: Heteroepitaxy of Dissimilar Materials

D: Atomic Layer Growth and Processing

$\mathrm{E}$ : Low Energy lon Beam and Plasma Modification of Materials

F: Rapid Thermal and Integrated Processing

G: Materials Reliability Issues in Microelectronics

$\mathrm{H}$ : Mechanical Behavior of Materials and Structures in Microelectronics

I: Contamination Control in Microelectronics

$\mathrm{J}$ : Materials Science of High Temperature Polymers for Microelectronics

$\mathrm{K}$ : Polymeric Alloys

L: Polymer Lifetimes

M: Polymeric Materials for Integrated Optics and Intormation Storage

N Materials for Optical Information Processing

O: Molecular Tribology

P: Interfaces in High Temperature Superconducting Systems

Q: Structure/Property Relationships for Metal/Metal Interfaces

R: Phase Transformation Kinetics in Thin Films

S: Magnetic Thin Films, Multilayers and Surfaces

T: Magnetic Materials: Microstructure and Properties

U: Synthesis/Characterization and Novel Applications of Molecular Sieve Materials

V: Modern Perspectives on Thermoelectrics and Related Materials

W: Environmentally Conscious Materials Processing

$X:$ Frontiers of Materials Research

\section{Preregistration}

Preregister by telephone, (412) 367-3003 or FAX (412) 367-4373, with your VISA, Mastercard or Diners Club card. Ask for Meeting Registration and your preregistration will be completed for you. Telephone preregistrations are accepted between 8:00 a.m. and 5:00 p.m. Eastern time, Monday through Friday. Confirmations will be mailed within 10 working days.

Materials Research Society

9800 McKnight Road

Pittsburgh, PA 15237

Telephone (412) 367-3003

FAX (412) 367-4373 